\title{
Exploring the Effect of Boarding and Alighting Ratio on Passengers' Behaviour at Metro Stations by Laboratory Experiments
}

\author{
Sebastian Seriani $\mathbb{D},{ }^{1}$ Rodrigo Fernandez, ${ }^{1}$ Nattanon Luangboriboon, ${ }^{2}$ and Taku Fujiyama ${ }^{2}$ \\ ${ }^{1}$ Faculty of Engineering and Applied Sciences, Universidad de Los Andes, Monseñor Álvaro del Portillo 12455, Santiago, \\ Las Condes, Región Metropolitana, Chile \\ ${ }^{2}$ Civil Environmental and Geomatic Engineering, University College London, Chadwick Building, Gower St., London, WC1E 6BT, UK
}

Correspondence should be addressed to Sebastian Seriani; sseriani@miuandes.cl

Received 14 December 2018; Revised 14 March 2019; Accepted 7 April 2019; Published 2 May 2019

Guest Editor: Milad Haghani

Copyright (C) 2019 Sebastian Seriani et al. This is an open access article distributed under the Creative Commons Attribution License, which permits unrestricted use, distribution, and reproduction in any medium, provided the original work is properly cited.

\begin{abstract}
The objective of this work was to study the effect of the ratio between passengers boarding and alighting on the passengers' behaviour at metro stations. A mock-up of a vehicle and the relevant portion of the platform was built to run a series of simulation experiments at University College London's Pedestrian Accessibility and Movement Environment Laboratory (PAMELA). Different scenarios were tested based on the next generation London Underground trains. The scenarios were classified according to different load conditions. Four types of behaviour are described. In most cases boarding is first, and passengers compete for space to enter the train. In the case of alighting, first passengers are faster than the rest of alighters due to the space available on the platform as boarding passengers give way to those who are getting off the train. In addition, alighters form lanes of flow depending on the number of passengers waiting to board the train on the platform. With respect to the train, if the density inside the train is higher than 4 passengers per square metre, then the flow at the doors starts to decrease. More experiments are needed to study the relationship between platform density and boarding and alighting time.
\end{abstract}

\section{Introduction}

The platform train interface (PTI) is a very complex space where most interactions occur between passengers boarding and alighting [1]. The way (e.g., movement) that passengers go from the platform to the train (boarding) or from the train to the platform (alighting) is a very important issue that affects the efficiency and safety of metro systems. In the case of London Underground (LU) [2], the total network provides around 4.69 million trips per day with a high peak of demand between 8 and 9 a.m., requiring one train every 2 or 3 minutes at metro stations such as Green Park (77,242 trips/weekday) on the Jubilee Line.

One of the main problems at the PTI is that passengers stay too long in the process of boarding and alighting. When the number of passengers boarding and alighting increases, crowding situations can be reached at stations.
Crowding influences the dwell time, which is the time each vehicle remains stopped at the station when transferring passengers [3]. The dynamic part is defined as the boarding and alighting time (BAT), whilst the static part includes the time of opening and closing of doors. The dwell time depends on the number of passengers boarding and alighting and their speed. The speed of passengers depends on different design variables such as height and distance between the train and the platform, the number and width of doors, and the layout inside the train. In addition, the speed of passengers is influenced by operation variables such as the density of passengers on the platform and inside the train, the behaviour of passengers (e.g., interactions), etc. Therefore, the dwell time affects the capacity of stations, delays and queues of trains, which in turn impacts on the frequency and regularity of the services, and therefore on the delays of passengers. 
To reduce crowding, manuals and recommendations are needed. In the case of the United Kingdom, the London Underground (LU) [4] proposes different recommendations which can be modelled and then compared to design thresholds. One of the most common indicators to represent the degree of congestion is the Level of Service or LOS [5], which represent walkways, stairs, and queues from a Level A (free flow) to a Level F (over the capacity). However, the LOS is based on average values in existing stations (e.g., number of passengers divided by the total platform area), and therefore it is difficult to identify which factors affect the passengers' behaviour and which part of the circulation space is more congested when the train design or station layout is changed.

To solve this problem a line of research has been developed based on laboratory experiments and observations. Some experiences have been started at University College London's Pedestrian Accessibility and Movement Environment Laboratory (PAMELA) and continue in other laboratories worldwide. Laboratories such as PAMELA are considered as an ideal opportunity to study different layout and load conditions such as the effect of different demand levels on the behaviour of passengers boarding and alighting, which is exactly the main objective of this research.

The main question of this research is how the boarding and alighting ratio $(\mathrm{R})$ affects the passengers' behaviour at the PTI. At stations with low demand level (i.e., noncrowded situations), train doors are opened for a fixed period of time; however when crowding increases train doors need to be opened for a longer period, and therefore the BAT increases. The hypothesis is that the behaviour would be the same under the same value of $\mathrm{R}$ no matter what the number of passengers boarding and alighting is.

The specific objectives are to (a) review the literature related to the variables that affect the passengers' behaviour and their effect on BAT, (b) simulate the boarding and alighting process at PAMELA for different values of $\mathrm{R}$, and (c) identify the type of behaviour according to each value of $R$ at the PTI.

This paper is composed of five sections. The next section describes existing studies that measured the passengers' behaviour and their effect on the BAT, followed by a section that explains the methods of this work. The fourth section presents the laboratory results. Finally, the discussion and further work are presented.

\section{Literature Review}

According to RSSB [6], four types of factors can affect the behaviour of pedestrians in public transport environments: presence of other people (e.g., density on the platform or personal space), physical design of the train carriage (e.g., width of the platform, number of train doors, or position of the seats), information provided to pedestrians (e.g., maps, on-board displays, and on-train announcements), and environment (e.g., weather). In the case of railway and metro systems, the presence of other people is considered the most important factor that influences the passengers' behaviour. When passengers are walking with a density of more than 2 passengers per square metre, or more than 5 pass $/ \mathrm{m}^{2}$ in a waiting area (e.g., queuing) [4], then a crowded situation is reached.

However, according to Cox et al. [7] there is a difference between density (physical characteristics of the environment) and crowding (psychological phenomenon) because a highdensity situation is not always perceived as crowded with a high level of stress. The authors [7] proposed a model with a high level of density and perception of crowding and stress level and also identified the relationship between crowding and risk safety. Similarly, Evans and Wener [8] studied high density and stress while commuting in trains where passengers have to sit next to others. The authors found that when the density increased, passengers perceived a high stress level. For Still [9], crowding is also related to the perception of risk and safety. The author states that the use of typical manuals and standards is not an ideal method to measure the risk and safety of passengers as they are "cut and paste" solutions from other realities. Therefore, the space of passengers is related to situations in terms of physical measurements, i.e., as a function of density and capacity on the platform and train, but also as a psychological dimension which is more about the perception of crowding.

To capture crowding in railway and metro systems Lam et al. [10] proposed a binary logit model to represent discomfort of passengers. The authors used interviews as a physical measurement based on the LOS of Fruin [5] and degree of crowding on the platform and inside the train. Similarly, to study the effect on the level of stress and feeling of exhaustion, Mahudin et al. [11] proposed a model to measure crowds based on psychological aspects of crowds (dense, disorderly, confining, chaotic, disturbing, cluttered, and unpleasant), evaluation of the environment where the crowd is situated (stuffy, smelly, noisy, and hot), and how crowds react in specific situations (squashed, tense, uncomfortable, distracted, frustrated, restricted, hindered, stressful, and irritable). Recently, Kim et al. [12] identified that people avoid delays caused by crowding and the stress caused by crowding, such as lack of availability of seats, and avoid other passengers or worry about sexual harassment. To measure delays, the authors used the dwell time (e.g., delay inside train and transferring), to measure stress they used the passenger load, and to collect the path choice of passengers they used "smart card" data. However, according to Preston et al. [13], in short commuter journeys crowding is based on stress and physical discomfort, while in long distance services the space to relax and use the journey productively is much more important for passengers. Other authors [14] have studied the concentration of passengers boarding at railway platforms, in which bigger clusters are not necessarily related to a higher density due to crowding at the station (e.g., passengers move along the platform to avoid contact with other passengers). Passengers tend to wait for the train near the entrance of the platform, especially closer to staircases and ramps [15]. Moreover, Oliveira et al. [16] found that the distribution of passengers on the platform is related to crowding, in which an evenly distribution of boarding can reduce the dwell time. The authors studied the behaviour in rail stations using video footage. 
Crowding is also related to the dynamic part of the dwell time, i.e., the boarding and alighting time (BAT). In the case of linear models, the Transit Capacity and Quality of Service Manual [3] states that the $t_{d}$ is influenced by the time needed to open and close the doors, the number of passengers boarding and alighting, and the average time each passenger takes to board and alight. In the case of nonlinear models, Lin and Wilson [17] studied the dwell time in light trains of one-car and two-car vehicles as a function of the number of boarding, alighting, and on-board passengers. Similarly, Fernadez et al. [18] calibrated the dwell time for the case of Transantiago in Chile, in which the average boarding time was $40 \%$ higher than the alighting time in the metro system. In the case of LU some authors $[19,20]$ have used the well-known LU Train Service Model to describe the BAT as part of the station stop time (SS). The SS depends on the number of passengers boarding and alighting, number of doors per car, peak door/average door factor, number of seats per car, number of through passengers, and door width factor. Recently, Tang et al. [21] modelled the behaviour of passengers at the PTI of high speed railway stations. The authors reported that the efficiency of the boarding process is influenced by the passengers' inflow rate and the entrance choice behaviour.

Different field studies have been done by Li et al. [22] to support the different models in order to study the BAT. In relation to the width of doors, Wiggenraad [23] found that wider doors decreased the BAT by $10 \%$. The author studied five door widths in existing Dutch trains: $800 \mathrm{~mm}, 900 \mathrm{~mm}$, $1100 \mathrm{~mm}, 1300 \mathrm{~mm}$, and $1900 \mathrm{~mm}$. In addition, Heinz [24] reported that the BAT can be increased when the number of vertical steps is increased. The author studied 18 different entrance designs at Swedish trains with level access, 2 steps, and 3 steps. The same author [24] found that a horizontal gap of $150 \mathrm{~mm}$ or more increased the BAT. Harris et al. [25] studied that the relationship between door width and capacity is not linear. The authors analysed a range of door widths, from $0.80 \mathrm{~m}$ to $1.80 \mathrm{~m}$, in which the flow rate at doors is influenced by the available space on the platform and inside the train. Recently, Barron et al. [26] compared 33 metro systems worldwide to study the effect of platform doors (e.g., platform edge doors). The authors found that these elements had a negative impact on the dwell time, reaching an extra time between 4 and $15 \mathrm{~s}$ at the station.

However, field studies are limited to the type of vehicles and stations existing at the time of study. Therefore, it could be difficult to change the layout of the station or buy new vehicles to calibrate the dwell time and identify their effect on the passengers' behaviour. In addition, it is impossible to control all the factors that influence the boarding and alighting for each observation which are classified according to RSSB [6].

To solve this, a line of researches based on laboratory experiments and observation have been started at PAMELA and continued in other laboratories worldwide. These experiments have been very useful to single out the influence of a particular variable because only a certain variable could be changed while keeping the other variables the same. One of the first laboratory studies was reported by Fernandez et al. [27], in which a simulated experiment represented the boarding and alighting process. In the experiment two door widths $(0.80 \mathrm{~m}$ and $1.60 \mathrm{~m})$ were tested. The authors found that wider doors $(1.60 \mathrm{~m})$ reduced the alighting time by $40 \%$. That study was followed at the Universidad de los Andes's Human Dynamic Laboratory (HDL) [28], in which the BAT was influenced by the vertical handrails, waiting areas on the platform, and the use of one-way doors. Recently, de Ana Rodriguez et al. [29] reported that the use of platform edge doors has no relevant impact on the BAT; however passengers change their behaviour by queuing at the side of the doors rather than waiting in front of the doors. Following this study Seriani et al. $[30,31]$ studied the interaction and passenger space at PAMELA, in which passengers reached a high interaction near the doors and it decreased as the distance from the doors increased because of the availability of space to board or alight.

In relation to the height between the train and the platform, laboratory experiments at PAMELA have shown that the use of steps can be considered an obstacle for passengers boarding and alighting. In this case Holloway et al. [32] simulated 60 passengers boarding and alighting with one single door and three different steps: $20 \mathrm{~mm}$ (zero step), $350 \mathrm{~mm}$ (2 steps), and $510 \mathrm{~mm}$ (3 steps). The authors [32] found that boarding passengers spent more time (4.13s on average) than those who were alighting (3.68s on average), in which $40 \%$ of them felt it difficult to use steps. Similarly, Daamen et al. [33] performed different experiments at Delft University, in which small vertical gaps increased the capacity of doors. At HDL Fernandez et al. [34] presented the relationship between door width and discharge rate. The authors [34] found that for a door width of $1.65 \mathrm{~m}$ the best vertical may be $150 \mathrm{~mm}$. In such a case, the alighting rate is 1.6 pass/s. Nonetheless, [34] only considered passenger alighting, and Fujiyama et al. [35] stated that for a bidirectional flow (boarding and alighting) the station and vehicle should be designed with a vertical gap of $50 \mathrm{~mm}$, reaching a maximum flow of 1.42 passengers per second. Moreover, Karekla and Tyler [36] proposed a model to predict the dwell time based on laboratory experiments, in which a small vertical gap can reduce the dwell time by $8 \%$. When accessibility is not achieved over the complete platform, Tyler et al. [37] proposed to build platform humps, in which only a part of the platform is raised to be level with the train. The authors tested different slopes and cross-fall gradients at PAMELA, in which the trains should not stop in front of the ramp.

In addition, laboratory experiments can be used to calibrate pedestrian models. For example, Rudloff et al. [38] presented a social force model to predict the BAT in which parameters were calibrated using experiments. The authors found that the BAT decreased as the door width increased, reaching a minimum overall value of $24.93 \mathrm{~s}$ for a door 1.85$\mathrm{cm}$ wide. To represent similar situations, Kretz et al. [39] studied 10 different widths of bottlenecks (in a range of $40 \mathrm{~cm}$ to $160 \mathrm{~cm}$ ), in which a $90 \mathrm{~cm}$ width allowed to pass two or more pedestrians. Hoogendoorn and Daamen [40] found that the capacity of a bottleneck did not increase linearly with a gradual increase in the width of the doors but increased in stepwise fashion. When pedestrians are formed into lanes of flow, the capacity will be increased only if a new lane is 


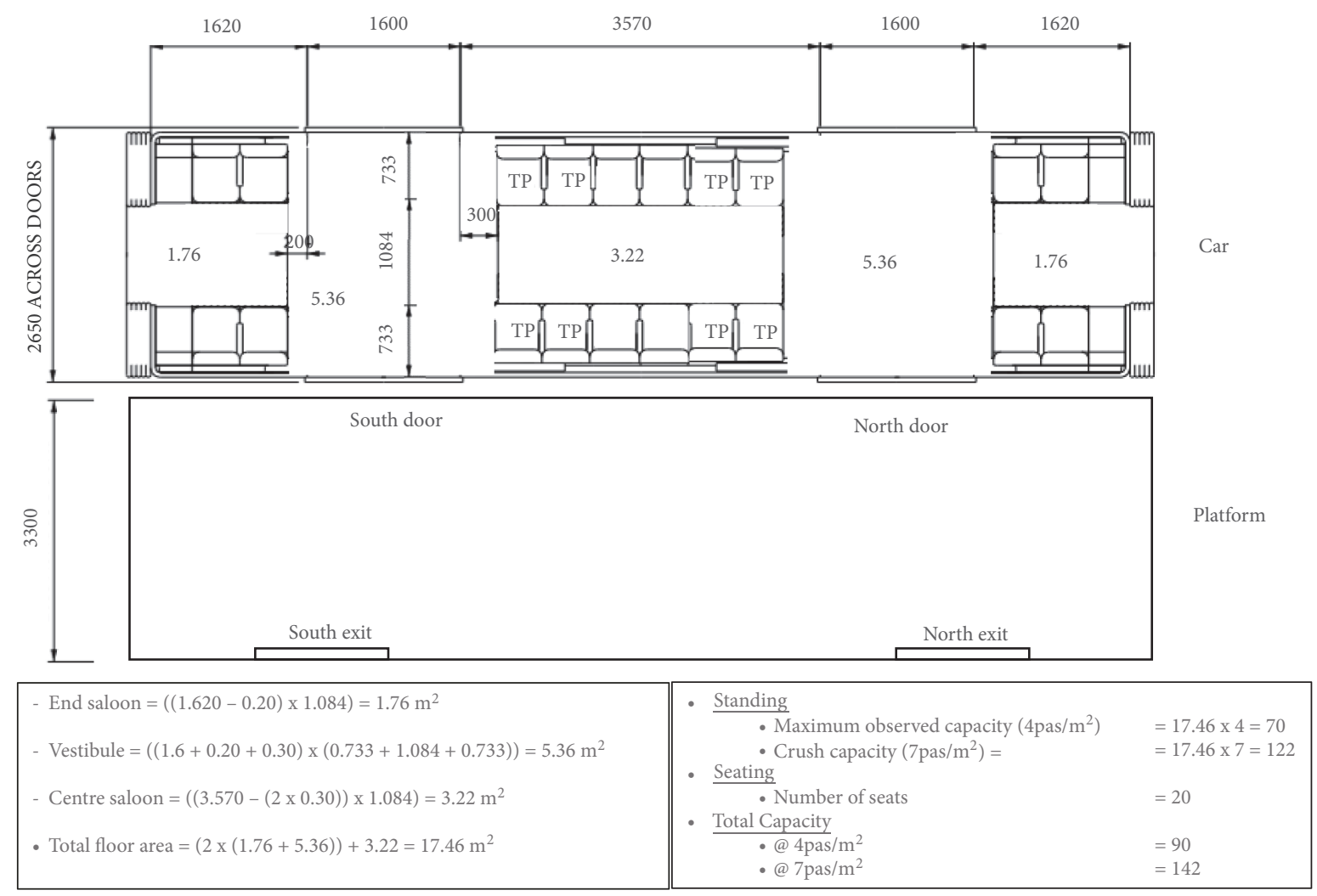

FIGURE 1: Drawing, dimensions $(\mathrm{mm})$, and areas calculations $\left(\mathrm{m}^{2}\right)$ for the simulated experiments at PAMELA.

formed. The authors defined the "zipper effect" when two lanes of pedestrians overlapped, reaching a distance between pedestrians of about $45 \mathrm{~cm}$, which is less than the body breadth $(50$ or $60 \mathrm{~cm})$. This is caused because pedestrians need more space to move forward than to move laterally. Similar to [39], Seyfried et al. [41] simulated experiments using unidirectional flow in a corridor with a bottleneck cantered. The authors reported that density in front of the bottleneck has a major impact on the flow and around $70 \mathrm{~cm}$ width the zipper effect is formed. More recent studies [42] reported that a linear dependency is between the flow and the bottleneck width up to $5 \mathrm{~m}$. In addition, the same authors [42] identified that the density inside the bottleneck keeps the same as the width of the bottleneck increased, but the density in front of bottleneck decreased. Moreover, Adrian et al. [43] studied five bottlenecks widths: $1.2 \mathrm{~m}, 2.3 \mathrm{~m}, 3.4 \mathrm{~m}$, $4.5 \mathrm{~m}$, and $5.6 \mathrm{~m}$. The authors used the Voronoi density using the location of the head of each participant, in which the corridor width and the motivation of participants are important factors to determine if pedestrians start queuing or pushing.

In spite of different research being done, more detailed research is needed to identify the effect of the boarding and alighting ratio on the passengers' behaviour, and therefore on the BAT. The observations made from the results of the experiments presented in this paper would fill gaps and reconfirm important points in relation to existing studies.

\section{Method}

3.1. Geometrical Layout and Variables. The method used in this research was based on real-scale laboratory experiments at PAMELA. The main variables used in these methods were selected according to the classification proposed by [1]. The authors used three types of variables: physical (i.e., vertical and horizontal gap, width of doors, and width and length of platforms), spatial (i.e., number of seats and setback), and operational (i.e., density of passengers, BAT, and time for each passenger to board and alight).

In relation to physical and spatial variables, the laboratory (or the experimental setting) consisted of a simulated experiment of a carriage and the relevant portion of the platform in front of the doors (see Figures 1 and 2). The carriage was configured with a set of parameters representative of a next generation LU train: 2 double $1.60 \mathrm{~m}$ wide doors, 12 fixed seats ( 4 in the centre and 4 at each end), 8 tip-up seats ( 2 on each side of the fixed central seating), a setback of $200 \mathrm{~mm}$ between the door and the end seats, and a setback of $300 \mathrm{~mm}$ between the door and the centre seats. The horizontal gap between the train and the platform was $90 \mathrm{~mm}$ and the vertical gap was $170 \mathrm{~mm}$.

With respect to operational variables, different loading conditions were tested at PAMELA (see Table 1), because demand is considered the main driver of passenger behaviour. The experiments were completed in four days in November 2014. The first two conditions (LC 0 and LC 1) 

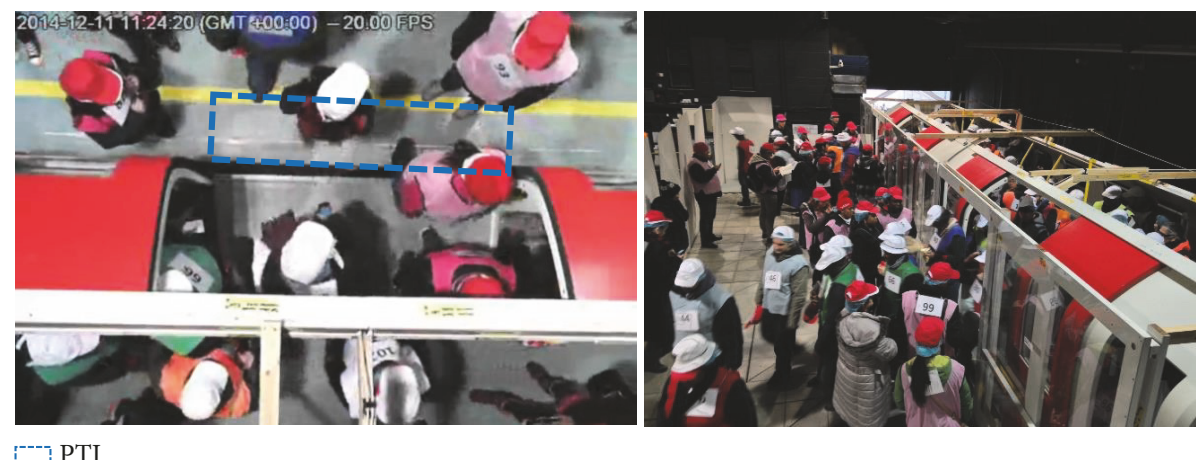

Figure 2: Different views of the simulated experiments at PAMELA.

TABLE 1: Load condition descriptions at PAMELA.

\begin{tabular}{lccccc}
\hline Load Condition code & Boarding per door & Alighting per door & On-board & $\mathrm{R}=$ Boarding/Alighting Ratio & Number of runs per scenario \\
\hline LC 0 & 55 & 0 & 0 & - & 2 \\
\hline LC 1 & 0 & 55 & 0 & 4 & 2 \\
\hline LC 2 & 40 & 10 & 10 & 0.25 & 20 \\
\hline LC 3 & 10 & 40 & 10 & 1 & 20 \\
\hline LC 4 & 20 & 20 & 30 & 4 & 20 \\
\hline LC 5 & 20 & 5 & 60 & 0.25 & 20 \\
\hline LC 6 & 5 & 20 & 60 & 1 & 20 \\
\hline LC 7 & 10 & 10 & 70 & - & 10 \\
\hline LC 8 & $55+$ crush & 0 & 0 & & \\
\hline
\end{tabular}

Note: All passengers on-board remain inside the train in each run.

were used to make participants feel familiarized with the experiments, while the last condition (LC 8) was performed to calculate the capacity of the carriage. The load conditions LC 2, LC 3, and LC 4 were classified as crowded situations at the PTI, while the noncrowded situations at the PTI are grouped in LC 5, LC 6, and LC 7. The values of boarding to alighting ratios $\mathrm{R}=4, \mathrm{R}=1$, and $\mathrm{R}=0.25$ were chosen in consultation with London Underground based on previous laboratory experiments at PAMELA and current demand levels at existing stations such as Green Park station in Jubilee Line. Using the definition in LUL [4] a crowded situation could reach a density of more than 5 passengers per square metre at the PTI, while the noncrowded situation presented less than 2 passengers per square metre at the PTI. In Table 1 the number of passengers boarding and alighting is considered for each double door, and on-board passengers remain inside the train while the boarding and alighting take place.

The experiments were recorded and then analysed with semiautomatic video analytics software. The cameras at PAMELA were located in the ceiling ( $4 \mathrm{~m}$ height), which enabled the recording of a space on the platform of only $3 \mathrm{~m}$ width by $5 \mathrm{~m}$ length in front of each train door (which produced an observed area on the platform $A_{p}=15 \mathrm{~m}^{2}$ ). The software Observer X11 [44] was used with a bespoke coding template. Two types of codes were used (to establish the time and to register an event) and 6 types of events were processed (train arrival, first passenger entering PTI, door opening, boarding or alighting, last passenger exiting PTI, and door closing), in which the period of analysis was between the times of the doors being opened and closed. The PTI was defined in consultation with Transport for London (TfL) as the space between the yellow line on the platform edge and the train doors.

The average boarding time per passenger $j$ was defined at PAMELA following Equation (1). In Equation (1), the total boarding time for passenger $j$ is obtained as the difference in time between the passenger boarding $j\left(t_{b j}\right)$ and the first passenger boarding $\left(t_{b 1}\right)$. Therefore, the number of passengers boarding is obtained from the opening to the closing of the doors minus the first passenger boarding. The same calculation is obtained for the average alighting time per passenger $i$ (see Equation (2)). In Equation (2), $t_{a i}$ is the time registered when the passenger $i$ alights and $t_{a 1}$ is the time registered when the first passenger alights.

$$
\begin{aligned}
& \overline{t_{b j}}=\frac{\left(t_{b j}-t_{b 1}\right)}{j-1} \\
& \overline{t_{a i}}=\frac{\left(t_{a i}-t_{a 1}\right)}{i-1}
\end{aligned}
$$

In Equation (1), $i=2, \ldots n$, in which $n$ is the total number of passengers boarding. Similarly, in the case of Equation (2) $j=2, \ldots m$, in which $m$ is defined as the total number of passengers alighting. The values of $n$ and $m$ varied depending 
on the load condition defined in Table 1. For example, in the case of $\mathrm{R}=4$ (LC 2) the value $n$ is equal to 40 passengers and $m$ is equal to 10 passengers. The total average boarding time per passenger $\left(\overline{t_{b n}}\right)$ can be obtained when $j=n$. The same calculation can be obtained for the total average alighting time per passenger $\left(\overline{t_{a m}}\right)$ when $i=m$.

In addition, the behaviour was observed according to RSSB [6]. In this study we only considered the factor related to people, i.e., the effect of the ratio between passengers boarding and alighting. Three variables were defined to study the behaviour. Firstly, the sequence of movement was analysed, i.e., when alighting and boarding started and its relationship with $t_{b j}$ and $t_{a i}$. Secondly, the formation of lanes of flow was identified each time a passenger alighted. If two passengers alight simultaneously, then two lanes of flow are reached. A single lane of flow was defined as one passenger alighting throughout the train doors. The last variable measured was the density inside the train each time a passenger boards and its relationship with the flow at the train doors. The density $(k)$ was defined as the ratio between the total number of passengers inside the train $\left(p_{v}\right)$ and the total floor area $\left(A_{f}\right)$. The variable $p_{v}$ is the sum of the number of passengers on-board (which remained constant in each run), the number of passengers waiting to alight, and the number of passengers who already board the train. From Figure $1, A_{f}$ $=17.46 \mathrm{~m}^{2}$; i.e., the floor area for each door is equal to $A_{f} / 2=$ $8.73 \mathrm{~m}^{2}$. The flow of passengers boarding $j\left(q_{b j}\right)$ is obtained as the inverse of the average boarding time per passenger $j$ (i.e., $\left.q_{b j}=1 / \overline{t_{b j}}\right)$.

To compare the mean between $\overline{t_{b n}}$ and $\overline{t_{a m}}$ for each value of $\mathrm{R}$, a Student's t-Test was performed in which the data were normally distributed with independent observations. The null hypothesis (Ho) indicates that the 2 samples have the same mean. An $\alpha=0.05$ (significance level) or $95 \%$ of confidence level was chosen for the statistical test. In addition, an ANOVA test single factor (significance level of 5\%) was done to compare if there were significant differences in $\overline{t_{b n}}$ and $\overline{t_{a m}}$ over the different values of $\mathrm{R}$. The null hypothesis was defined as the samples having the same mean.

3.2. Participants. The 110 participants recruited at PAMELA represented the boarding (red hats) and alighting (white hats) at the PTI. Each participant had a number and they formed 11 groups with different colour bibs. Participants were asked to complete a form to register for the experiments, which included the following details: name, email, gender, age, height, weight, and if he/she is a regular commuter or has any mobility impairments.

From the total of passengers at the experiments (110 passengers), $46 \%$ (50 passengers) were men and 54\% (60 passengers) were women. Most of them (78\%) were regular users of the London Underground (LU). With respect to their age, most of them were under 45 years old $(15 \%$ under 24 years old, $26 \%$ between 25 and 34 years old, 19\% between 35 and 44 years old, $27 \%$ between 45 and 59 years old, $7 \%$ between 60 and 64 years old, and 7\% more than 65 years old). The total passenger load tested in the scenarios LC 0 and LC 1 (defined in Table 1) was $8221 \mathrm{~kg}$ (including seated passengers). The average height of passengers was $170 \mathrm{~cm}$ with a deviation standard of $8 \mathrm{~cm}$.

Participants at the experiment were instructed to walk "naturally" as if they were boarding and alighting a train in the LU. All boarding passengers were instructed to enter the platform area and wait to board the train. After all passengers entered the platform area then the process of boarding and alighting began. Due to restrictions of space at PAMELA we did not consider passengers arriving at a specific distribution rate before or after the train arrived. To make sure that this behaviour was represented over time, random groups were chosen to board, alight, or remain inside the carriage. In addition, a complete sound system was provided in order to make the experiment feel real for the participants. The sound included the train arriving, braking, door opening alarm, door closing alarm, and departure.

The complete procedure ( 74 seconds approximately) was based on LU metro stations and started with an announcement: "Participants with colour $\mathrm{xx}$ : when the door opens, please alight the train. Participants with colour yy: when the door opens, please board the train." After this announcement, the sound effect starts ( 0 seconds), in which the sound of the train approaching is heard from the speakers (20 seconds). When the sound stops, then the door alert starts, and door starts opening (21 seconds). After 2 seconds the doors are full open. Next, another announcement is made (25 seconds): "let the costumer off the train first." Consequently, the last announcement is made (58 seconds): "please move right down inside the carriage and make use of all the available space." Ten seconds later door alter starts. Finally, door starts closing (72 seconds), and doors are fully closed (74 seconds).

The use of laboratory experiments could help to separate the effect of external factors that influence the movement of passengers such as social interactions, activities, and safety constraints. In addition, the laboratory environment is an ideal space to change one variable and keep the rest fixed. Therefore, PAMELA represents an ideal opportunity for researchers to test "what if" scenarios. However, this does not mean that the behaviour of passengers during the experiments is the same as the behaviour of passengers at existing stations. Thus, the experiments help to identify relative differences between scenarios, which would then be tested afterwards in existing stations. In previous experiments, Ana Rodriguez et al. [29] simulated the boarding and alighting when platform edge doors were installed at PAMELA and then compared to two existing stations in the LU. The authors [29] found that similar profiles of boarding and alighting were obtained between the experiments and the stations.

\section{Experiments at PAMELA}

4.1. Average Boarding and Alighting Time. Figure 3 shows the results of the experiments in the case of crowded situations at the PTI (load conditions LC 2, LC 3, and LC 4 in Table 1). The figure presents the total average boarding time per passenger $\left(\overline{t_{b n}}\right)$ and the total average alighting time per passenger $\left(\overline{t_{a m}}\right)$ for different values of $\mathrm{R}$. The $\overline{t_{b n}}$ and $\overline{t_{a m}}$ 


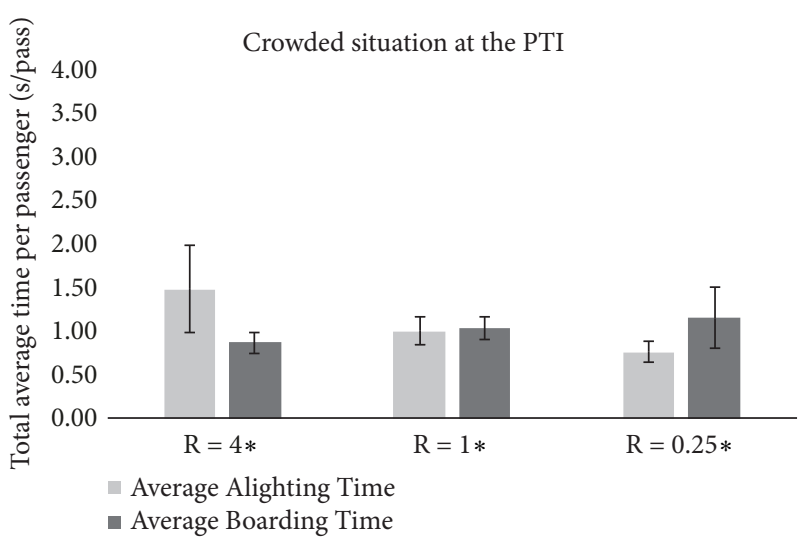

FIGURE 3: Total average boarding time per passenger $\left(\overline{t_{b n}}\right)$ and total average alighting time per passenger $\left(\overline{t_{a m}}\right)$ in crowded situations at the PTI.

are obtained according to Equations (1) and (2) defined in Section 3 for each of the 20 runs in each case of $\mathrm{R}$, respectively. In the case of $\mathrm{R}=4$ (i.e., 4 times more passengers boarding than alighting), $\overline{t_{a m}}$ reached $1.48 \mathrm{~s} /$ pass which is $70 \%$ higher than $\overline{t_{b n}}$. This is caused because the platform is crowded and passengers alighting have less available space to get off the train. As a consequence, a high interaction between passengers boarding and alighting is reached. On the other hand, when $\mathrm{R}=0.25$ (i.e., 4 times more passengers alighting than boarding), $\overline{t_{b n}}$ reached $1.15 \mathrm{~s} /$ pass which is $51 \%$ higher than $\overline{t_{a m}}$. In this case $(\mathrm{R}=0.25)$ passengers alighting have more space available to get off the train, and therefore less interaction is obtained with those passengers who are waiting to board the train. The case $\mathrm{R}=1$ presented no variation between $\overline{t_{b n}}$ and $\overline{t_{a m}}$ on average due to similar level of demand between passengers boarding and alighting. All these differences are significant according to Student's t-Test ( $\mathrm{p}$ value $<0.05$ ). In Figure $3, *$ shows that there are significant differences between $\overline{t_{b n}}$ and $\overline{t_{a m}}$ for each value of $\mathrm{R}$.

When comparing $\overline{t_{a m}}$ over the different values of $\mathrm{R}$, some relationship could be obtained in Figure 3. If $\mathrm{R}$ decreases (i.e., there are more passengers alighting than boarding), then $\overline{t_{a m}}$ decreases on average. The case $\mathrm{R}=4$ (10 passengers alighting per door) reached the highest value (1.48 s/pass), which is $48 \%$ more than $\overline{t_{a m}}$ in the case $\mathrm{R}=1$ ( 20 passengers alighting per door) and $94 \%$ more than $\overline{t_{a m}}$ in the case $\mathrm{R}$ $=0.25$ (40 passengers alighting per door). With respect to $\overline{t_{b n}}$, if $\mathrm{R}$ increases (i.e., there are more passengers boarding than alighting), then $\overline{t_{b n}}$ decreases on average. The case $\mathrm{R}=$ 0.25 (10 passengers boarding per door) presented the highest value (1.15 s/pass), which is $11 \%$ more than $\overline{t_{b n}}$ when $\mathrm{R}=1$ ( 20 passengers boarding per door) and $32 \%$ more than $\overline{t_{b n}}$ when $\mathrm{R}=4$ (40 passengers boarding per door). All these differences are significant according to the ANNOVA test single factor ( $p$ value $<0.05)$.

Similarly, Figure 4 presents $\overline{t_{b n}}$ and $\overline{t_{a m}}$ for different values of $\mathrm{R}$ in noncrowded situations at the PTI (load conditions LC 5, LC 6, and LC 7 in Table 1). Due to the similar level of demand, $\overline{t_{a m}}$ reached only a difference of $3 \%$ with respect to $\overline{t_{b n}}$ when $\mathrm{R}=1$. In fact this case $(\mathrm{R}=1)$ presented no

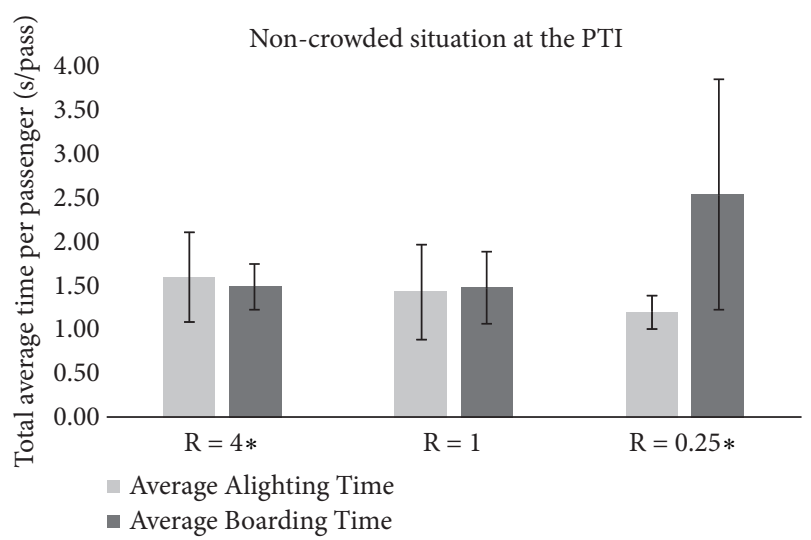

FIGURE 4: Total average boarding time per passenger $\left(\overline{t_{b n}}\right)$ and total average alighting time per passenger $\left(\overline{t_{a m}}\right)$ in noncrowded situations at the PTI.

significant differences ( $\mathrm{p}$ value $=0.147$ ) according to Student's $\mathrm{t}$-Test. It was expected to have the same differences observed in Figure 3 for the other two cases of $\mathrm{R}(\mathrm{R}=4$ and $\mathrm{R}=$ $0.25)$. However, when $\mathrm{R}=4, \overline{t_{a m}}$ is only $6 \%$ higher than $\overline{t_{b n}}$. This is caused because of the low number of passengers alighting (only 5) who are pressured to alight faster from those passengers who are waiting to board (20 passengers). When $\mathrm{R}=0.25$, this difference is much higher in which $\overline{t_{a m}}$ reaches almost the half of $\overline{t_{b n}}$ but also presented a higher standard deviation (1.31 s/pass) compared to the other cases. These differences are significant according to Student's t-Test ( $\mathrm{p}$ value $<0.05$ ). However, the situation of $\mathrm{R}=1$ reached no significant differences ( $\mathrm{p}$ value $=0.147$ ) between $\overline{t_{b n}}$ and $\overline{t_{a m}}$ due to the similar and low number of passengers boarding and alighting (only 10 passengers boarding and 10 passengers alighting). In Figure $4, *$ shows that there are significant differences between $\overline{t_{b n}}$ and $\overline{t_{a m}}$ for each value of $\mathrm{R}$.

In addition, some relationship can be obtained when comparing $\overline{t_{a m}}$ over the different values of $\mathrm{R}$ in Figure 4 . When $\mathrm{R}=4, \overline{t_{a m}}$ reached the highest which is $11 \%$ higher than $\overline{t_{a m}}$ in the case of $\mathrm{R}=1$ and $33 \%$ more than $\overline{t_{a m}}$ in the situation of $\mathrm{R}=0.25$. With respect to $\overline{t_{b n}}$, the case $\mathrm{R}=0.25$ presented the highest value (2.54 s/pass) which is $72 \%$ more than $\overline{t_{b n}}$ in the case of $\mathrm{R}=1$ and $70 \%$ higher than $\overline{t_{b n}}$ when $\mathrm{R}=4$. All these differences are significant according to the ANNOVA test single factor ( $\mathrm{p}$ value $<0.05$ ).

4.2. Sequence of Movement. From the laboratory experiments it was observed that alighting occurs first and then boarding; i.e., passengers on the platform give way to those who are alighting or wait for a gap in space to board the train. In the case of crowded situations at the PTI (load conditions LC 2, LC 3, and LC 4 in Table 1), Figure 5 shows the average boarding time per passenger $\mathrm{j}\left(\overline{t_{b j}}\right)$ and average alighting time per passenger i $\left(\overline{t_{a i}}\right)$. In the figure it can be observed that boarding started earlier when $\mathrm{R}=4$ compared to the cases of $\mathrm{R}=0.25$ and $\mathrm{R}=1$. This is caused due to the few passengers alighting (10 passengers) compared to those who were waiting to board the train ( 40 passengers) when $\mathrm{R}=4$. Consequently, $\overline{t_{b j}}$ in $\mathrm{R}=4$ is smaller than the other two cases $(\mathrm{R}=1$ and $\mathrm{R}$ 

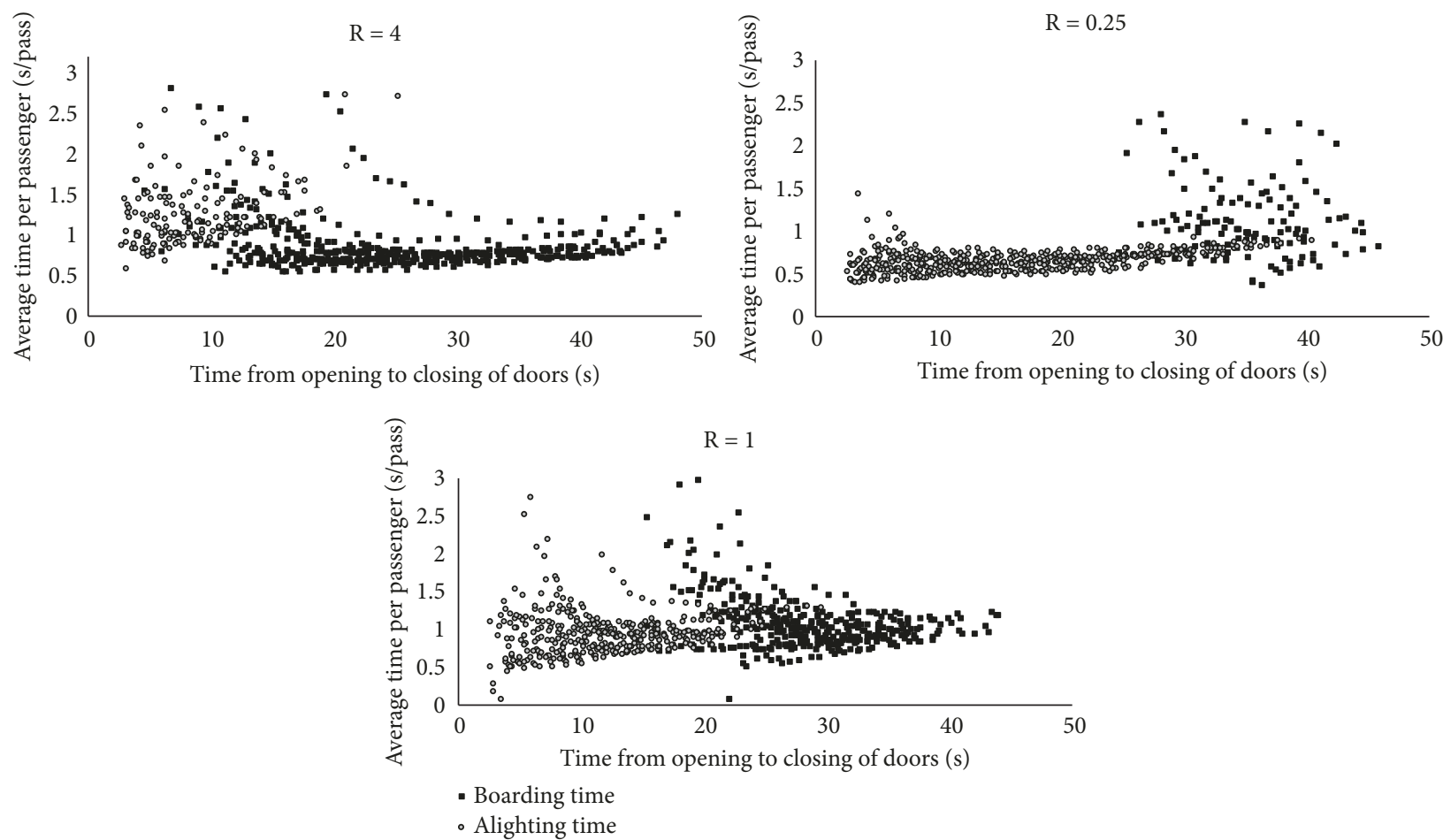

FIGURE 5: Average boarding time per passenger $\mathrm{j}\left(\overline{t_{b j}}\right)$ and average alighting time per passenger $\mathrm{i}\left(\overline{t_{a i}}\right)$ at PAMELA when crowded situations are reached at the PTI.

$=0.25$ ) even though there were more passengers boarding. On the other hand, when there were 4 times more passengers alighting than boarding (i.e., $\mathrm{R}=0.25$ ), passengers on the platform almost wait until alighting was finished to board the train, and therefore $\overline{t_{b j}}$ increased.

From Figure 5 it can be also observed that the first passengers alighting reached a lower $\overline{t_{a i}}$ compared to the last passengers alighting. For example, when $\mathrm{R}=4$ and $\mathrm{R}=1$ the first passengers alighting reached a value of $\overline{t_{a i}}$ in the ranges of $0.5 \mathrm{~s} /$ pass and $1.0 \mathrm{~s} /$ pass, while the last passengers alighting obtained a $\overline{t_{a i}}$ of $1.5 \mathrm{~s} /$ pass or more. In the case of $\mathrm{R}=0.25$, a smooth variation is presented between the first passengers alighting ( $\overline{t_{a i}}$ is around $0.5 \mathrm{~s} / \mathrm{pass}$ ) and the last passengers alighting ( $\overline{t_{a i}}$ is almost $0.9 \mathrm{~s} /$ pass $)$. This could be caused because the first passengers alighting have more space at the PTI to move (as passengers boarding give way to those who are alighting) than the rest of passengers who need to follow the person in front of them to avoid collision with those passengers boarding. In addition, the case of $\mathrm{R}$ $=0.25$ presented only 10 passengers waiting to board the train; therefore passengers alighting have less interaction with boarding passengers and they reach a lower value of $\overline{t_{a i}}$ compared to the other two cases of $\mathrm{R}(\mathrm{R}=4$ and $\mathrm{R}=$ 1). Another reason is that first passengers alighting could be closer to the train doors (e.g., they accommodate their position to alight first) than the rest of alighters who need to avoid contact with those passengers on-board; however it was not possible to obtain the exact location inside the train due to the position of the cameras in which each passenger's head was obstructed by the structure of the carriage.
The same sequence of movement is observed in the case of noncrowded situations (see Figure 6); i.e., alighting is first and then boarding and first passengers alighting reached a lower $\overline{t_{a i}}$ compared to the last passengers alighting. Therefore, the sequence of movement is the same under the same value of $\mathrm{R}$ no matter the number of passengers boarding and alighting. However, the demand level affects the variability on the $\overline{t_{b j}}$ and $\overline{t_{a i}}$. For example, in the case of $\mathrm{R}=0.25$ the crowded situation (LC 3 ) reached a $\overline{t_{a i}}$ in a range between $0.4 \mathrm{~s} /$ pass and $1.5 \mathrm{~s} /$ pass, while the range in the noncrowded situation (LC 6) varied between $0.5 \mathrm{~s} /$ pass and $3.0 \mathrm{~s} /$ pass. A Student's $\mathrm{t}$-Test ( $\mathrm{p}$ value $<0.05$ ) was performed to compare $\overline{t_{a i}}$ between the crowded and noncrowded situations for each value of $\mathrm{R}$. The results show that all the cases presented significant differences. A similar comparison was done with respect to $\overline{t_{b j}}$, in which the differences are also significant between the crowded and noncrowded situations for each value of $\mathrm{R}$.

4.3. Formation of Lanes of Flow. Another behaviour is observed with respect to the formation of lanes of flow in the alighting process. It was expected that the formation of lanes of flow will be the same under the same value of $\mathrm{R}$ no matter the number of passengers boarding and alighting. However, the formation of lanes of flow varied depending on the value of $\mathrm{R}$ and the number of passengers boarding and alighting. The only cases in which two lanes were formed were obtained in the crowded situations when $\mathrm{R}=4$ (LC 2) and $\mathrm{R}$ $=0.25$ (LC 3). In the case of $\mathrm{R}=4,152$ alighting passengers were registered, in which 12 of them formed two lanes of flow (i.e., $8 \%$ of the observed alighters) and the rest only formed 

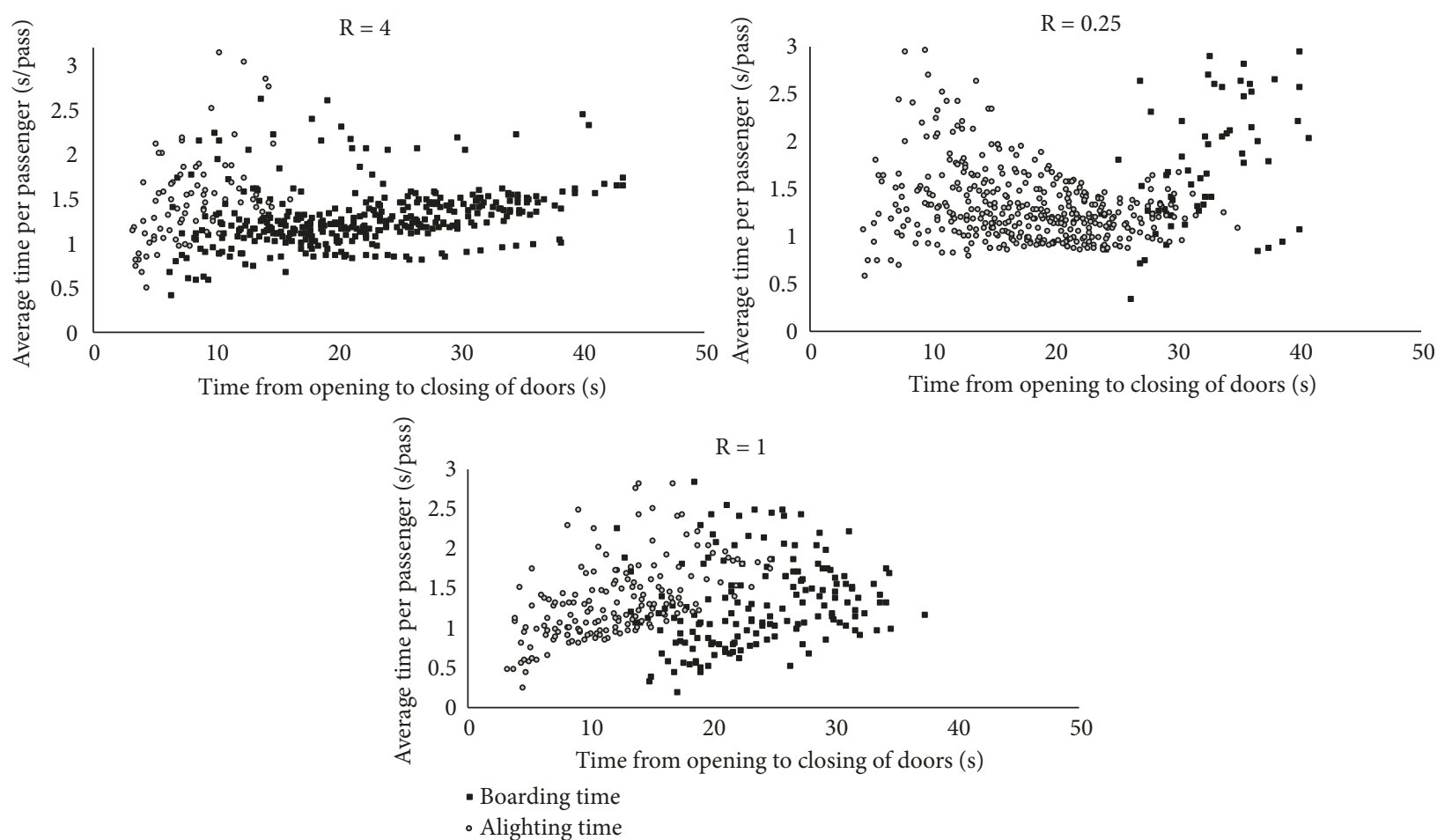

FIGURE 6: Average boarding time per passenger $\mathrm{j}\left(\overline{t_{b j}}\right)$ and average alighting time per passenger $\mathrm{i}\left(\overline{t_{a i}}\right)$ at PAMELA when noncrowded situations are reached at the PTI.
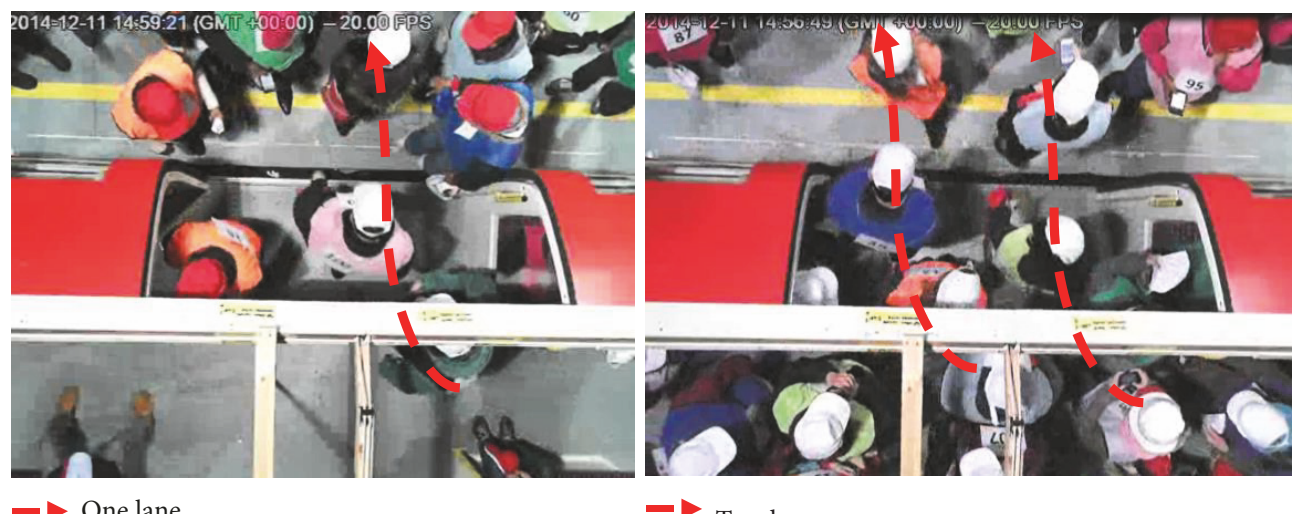

$\rightarrow$ One lane

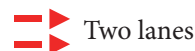

FIGURE 7: Example of formation of lanes of flow for alighting passengers. One narrow lane of flow when $\mathrm{R}=4$ (left) and two lanes of alighting flow when $\mathrm{R}=0.25$ (right) in crowded situations.

one narrow lane for alighting. For the situation of $\mathrm{R}=0.25$, 471 alighting passengers were recorded, in which 179 of them presented two lanes for alighting (i.e., 38\% of the observed alighters), while the rest only formed one narrow lane.

Figure 7 shows an example of formation of lanes of flow in crowded situations. When $\mathrm{R}=4$, then only one narrow lane of flow is formed for those passengers alighting. This is caused because when $\mathrm{R}=4$, and there are four times more passengers boarding than those who are alighting; therefore the platform is crowded and alighters need to compete for space to get off the train. On the other hand, when $\mathrm{R}=0.25$ up to two lanes of flow are formed for those passengers alighting, due to the low number of passengers on the platform (there are four times more passengers alighting than boarding). In the case of $\mathrm{R}=$ 1 , the formation of lanes of flow is between the two other cases of $\mathrm{R}=4$ and $\mathrm{R}=0.25$.

4.4. Density inside the Train. In the case of crowded situations (see Figure 5) the first passengers boarding reached a higher $\overline{t_{b j}}$ compared to the last passengers boarding due to the influence by those passengers alighting and the density inside the train. For example, when $\mathrm{R}=4$ the first passengers boarding reached a value of $\overline{t_{b j}}$ of $2.5 \mathrm{~s} /$ pass or more, while the last passengers boarding obtained $\bar{a} \overline{t_{b j}}$ of around $1.0 \mathrm{~s} /$ pass. 


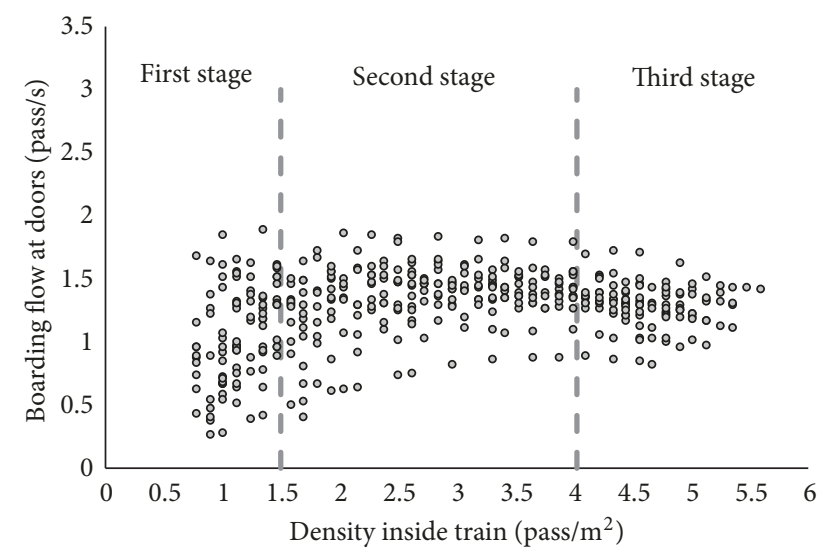

FIGURE 8: Relationship between the flow of passengers boarding at the doors and the density inside the train at PAMELA in the case of LC $2(\mathrm{R}=4)$.

The same situation is presented in the other two cases of $\mathrm{R}$ ( $\mathrm{R}=1$ and $\mathrm{R}=0.25$ ). It was expected that this behaviour will be the same under the same value of $\mathrm{R}$ no matter the number of passengers boarding and alighting. However, in the noncrowded situations (see Figure 6) the first passengers boarding are not influenced by those passengers alighting or the density inside the train. In all the cases of $\mathrm{R}$, the first passengers boarding presented a lower $\overline{t_{b j}}$ compared to the last passengers boarding. This could be caused due to the low level of demand in the noncrowded situation, in which less than 2 pass $/ \mathrm{m}^{2}$ are reached at the PTI.

When the alighting is finished the density inside the train starts to increase up to a point in which the boarding flow at the doors decreases. In the case when the platform is congested, i.e., $\mathrm{R}=4$ (LC 2), some similarities in behaviour were obtained. Figure 8 presents three stages to relate density inside the train and flow of boarding passengers when $\mathrm{R}=4$ (LC 2). A first stage is produced between the first passenger alighting and the last passenger alighting. At the end of this stage the density inside the train is 1.50 pass $/ \mathrm{m}^{2}$ on average (standard deviation of 0.64 pass $/ \mathrm{m}^{2}$ ) and the flow at the doors is 1.09 pass/s on average (standard deviation of $0.37 \mathrm{pass} / \mathrm{s})$. A second stage is reached from the moment the alighting process is finished until the flow of passengers boarding at the doors started to decrease. At the end of this stage the density on the train is 4.03 pass $/ \mathrm{m}^{2}$ on average (standard deviation of 0.49 pass $/ \mathrm{m}^{2}$ ) and the flow at the doors is $1.38 \mathrm{pass} / \mathrm{s}$ on average (standard deviation of 0.19 pass/s). A third stage is obtained when the flow of passengers boarding at the doors started to decrease. This is caused because passengers boarding are influenced by the density inside the train. Because of this type of behaviour, it could be recommended to close the doors at the moment when the flow started to decrease, i.e., at the third stage. In this case ( $\mathrm{R}$ $=4$, LC 2), if the doors are closed at the third stage, then $78 \%$ of passengers will complete the process of boarding, while the rest (22\% passengers) would need to wait for next train. This means that 10 passengers should wait for the next train on average from the total number of passengers boarding
(40 passengers). Consequently, there is $26 \%$ boarding time saved (11.07 $\mathrm{s}$ on average), and therefore the dwell time will be reduced.

\section{Discussion and Future Work}

This work studied the effect of the ratio (R) between boarding and alighting on the behaviour of passengers, and therefore on the boarding and alighting time at the platform train interface (PTI). The approach used laboratory experiments at Pedestrian Accessibility and Movement Environment Laboratory (PAMELA, University College London) based on the next generation London Underground trains.

The results of the laboratory experiments showed the importance of $\mathrm{R}$ (ratio between passengers boarding and alighting) on the average boarding time per passenger $\left(\overline{t_{b j}}\right)$ and the average alighting time per passenger $\left(\overline{t_{a i}}\right)$. The hypothesis of our research could be refuted as the behaviour was not always the same for the same values of $\mathrm{R}$ due to the differences in the level of demand. Therefore, the number of passengers boarding and alighting is another influencing factor on passenger behaviour.

With respect to crowded situations, not always a high number of passengers boarding will increase the total average boarding time per passenger $\left(\overline{t_{b n}}\right)$. The case $\mathrm{R}=4$ presented the lowest value of $\overline{t_{b n}}$ compared to the other two cases (R $=0.25$ and $\mathrm{R}=1)$. The same conclusion is obtained for the total average alighting time per passenger $\left(\overline{t_{a m}}\right)$, in which the lowest value was obtained when $\mathrm{R}=0.25$. These differences were statistical with a level of confidence of 0.05 . In addition, when $\mathrm{R}=4, \overline{t_{a m}}$ is bigger than $\overline{t_{b n}}$. This is caused due to the small available space to move for those 10 passengers alighting as there are 40 passengers waiting to board, reaching a high interaction between them. On the other hand, when $\mathrm{R}=0.25$, $\overline{t_{a m}}$ is smaller than $\overline{t_{b n}}$, due to similar reasons. In this case $(\mathrm{R}=$ 0.25 ) those 10 passengers waiting to board need to look for a gap in space to board the train, which is difficult considering that 40 alighting passengers are getting off the train. The case $\mathrm{R}=1$ presented no major differences between $\overline{t_{a m}}$ and $\overline{t_{b n}}$ due to the similar number of passengers boarding and alighting. To better represent the relationship between demand level and boarding/alighting time, this ratio $\mathrm{R}$ should be included in dwell time models presented in [3, 17-20, 22].

In the case of noncrowded situations at the PTI, it was not possible to establish major differences between $\overline{t_{a m}}$ and $\overline{t_{b n}}$ when $\mathrm{R}=4$. It seems that the low number of passengers alighting did not affect the behaviour of those passengers waiting to board. The case $\mathrm{R}=1$ also presented no important differences between $\overline{t_{a m}}$ and $\overline{t_{b n}}$ which is similar to the crowded situations for the same value of R. However, when $\mathrm{R}=0.25$ the difference between $\overline{t_{a m}}$ and $\overline{t_{b n}}$ was much bigger. This could be caused because passengers boarding wait until alighting is almost finished to board, which is a similar behaviour in crowded situations. In these cases (noncrowded situations), the results are in concordance with different manuals [3], in which the train doors can be opened for a fixed period of time without problems of crowding at the PTI. 
In relation to the sequence of movement, similar to the observation done at existing stations by Harris et al. [19, 20] the results from the laboratory experiments showed that alighting is first and passengers boarding compete for a space to board the train. In addition, the first passengers alighting reached a lower $\overline{t_{a i}}$ compared to the last passengers alighting. This can be caused because passengers boarding give way to those who are alighting; therefore the first passenger that gets off the train has more space available than the rest of passengers.

Different from the laboratory experiments done by Dameen et al. [33], Fernandez et al. [34], and Fujiyama et al. [35], another behaviour observed at PAMELA was that the capacity of the train doors will not only depend on the door widths but also on the ratio $\mathrm{R}$. If the value of $\mathrm{R}$ increases, then the number of lanes of flow for those passengers alighting will decrease. This was only presented in the crowded situations, due to the high number of passengers boarding and alighting (reaching more than 4 pass $/ \mathrm{m}^{2}$ ).

The last type of behaviour is related to the density inside the train. When $\mathrm{R}=4$ (crowded situations), if the density is higher than 4 pass $/ \mathrm{m}^{2}$ the flow at the doors starts to decrease. Therefore, this could help to implement different crowd management measures such as to close the train doors before the boarding process finishes. In that case $(R=4)$, we could save up to $26 \%$ of the boarding time (i.e., about 11 s). This benefit can be very important to reduce dwell time at stations. In this sense, the results can complement other experimental studies related to crowd management measures such as that of Seriani and Fernandez [28].

The relationship between the flow of boarding passengers at the train doors and the density inside the train is not exactly the same as the relationship reported by different authors [39-43]. These authors used a confined space such as a corridor; however in our study the density is obtained inside the train, which is a separate place from the doors and platform. Considering the wide range of density inside the train there is little variation on the boarding flow at the doors. In addition, the statement that the flow decreases at high densities is only part of the results. In fact, the upper limit of flow decreases while the lower limit increases. In conclusion, the average boarding flow can be assumed to be independent of the on-board density, at least up to densities which were investigated. Further research will consider density classes to clarify this issue a bit better.

In conclusion, the use of laboratory experiments helped to test different situations (what if scenarios) in a controlled environment. This would be difficult to do in a real situation due to the different variables affecting the layout and vehicles of existing public transport systems. In addition, few laboratories such as PAMELA are built in the world, which has led us to be in a privileged position and to be able to perform new research. Further work is focused on new experiments to simulate the relationship between density and boarding and alighting time to identify which when to close the doors in more crowded situations (e.g., $\mathrm{R}=5, \mathrm{R}=6$, and $\mathrm{R}=7$ or more). This could be complemented with other measures such as the use of a waiting area or a "stay clear" to avoid alighting being blocked by passengers waiting in front of the doors.

\section{Data Availability}

The data used to support the findings of this study are included within the article.

\section{Conflicts of Interest}

The authors declare that there are no conflicts of interest regarding the publication of this paper.

\section{Acknowledgments}

The authors would like to thank all participants in the laboratory experiments at PAMELA. In addition, thanks are due to Transport for London for helping with the design of the experiment. This work was supported by the Scholarship Becas Chile, CONYCIT, Universidad de los Andes (Fondo de Ayuda a la Investigacion) and University College London.

\section{References}

[1] S. Seriani and R. Fernández, "Planning guidelines for metro-bus interchanges by means of a pedestrian microsimulation model in Chile," Transportation Planning and Technology, vol. 38, no. 5, pp. 569-583, 2015.

[2] TfL, London Underground Performance Reports. Entry and exit figures by station, Transport for London, London, UK, 2017, https://data.london.gov.uk/dataset/london-underground-performance-reports/resource/b6ab04fc-9062-4291-b514-7fa218073b4c.

[3] TRB, Transit Capacity and Quality of Service Manual, Transportation Research Board, Washington, DC, USA, 3rd edition, 2013.

[4] LUL, Station Planning Standards and Guidelines, London Underground Limited, London, UK, 2012.

[5] J. J. Fruin, "Designing for pedestrians: a level-of-service concept," Highway Research Record, vol. 377, pp. 1-15, 1971.

[6] RSSB, Management of on-train crowding Final Report, Rail Safety and Standards Board, London, UK, 2008.

[7] T. Cox, J. Houdmont, and A. Griffiths, "Rail passenger crowding, stress, health and safety in Britain," Transportation Research Part A: Policy and Practice, vol. 40, no. 3, pp. 244-258, 2006.

[8] G. W. Evans and R. E. Wener, "Crowding and personal space invasion on the train: Please don't make me sit in the middle," Journal of Environmental Psychology, vol. 27, no. 1, pp. 90-94, 2007.

[9] K. Still, Introduction to Crowd Science, CRC Press, Boca Raton, FL, USA, 2013.

[10] W. H. K. Lam, C.-Y. Cheung, and C. F. Lam, "A study of crowding effects at the Hong Kong light rail transit stations," Transportation Research Part A: Policy and Practice, vol. 33, no. 5, pp. 401-415, 1999.

[11] N. D. M. Mahudin, T. Cox, and A. Griffiths, "Measuring rail passenger crowding: scale development and psychometric properties," Transportation Research Part F: Traffic Psychology and Behaviour, vol. 15, no. 1, pp. 38-51, 2012. 
[12] K. M. Kim, S.-P. Hong, S.-J. Ko, and D. Kim, "Does crowding affect the path choice of metro passengers?" Transportation Research Part A: Policy and Practice, vol. 77, pp. 292-304, 2015.

[13] J. Preston, J. Pritchard, and B. Waterson, "Train overcrowding: Investigation of the provision of better information to mitigate the issues," Transportation Research Record: Journal of the Transportation Research Board, vol. 2649, pp. 1-10, 2017.

[14] G. Dell'Asin and J. Hool, "Pedestrian patterns at railway platforms during boarding: evidence from a case study in switzerland," Journal of Advanced Transportation, vol. 2018, Article ID 4079230, 11 pages, 2018.

[15] C. Fox, L. Oliveira, L. Kirkwood, and R. Cain, "Understanding users behaviours in relation to concentrated boarding: implications for rail infrastructure and technology," in Proceedings of the 15th International Conferenceon Manufacturing Research, London, UK, 2017.

[16] L. C. Oliveira, C. Fox, S. Birrell, and R. Cain, "Analysing passengers' behaviours when boarding trains to improve rail infrastructure and technology," Robotics and Computer-Integrated Manufacturing, vol. 57, pp. 282-291, 2019.

[17] T. M. Lin and N. H. M. Wilson, "Dwell time relationships for light rail systems," Transportation Research Record: Journal of the Transportation Research Board, vol. 1361, pp. 287-295, 1991.

[18] R. Fernandez, M. A. del Campo, and C. Swett, "Data collection and calibration of Passenger Service Time models for the Transantiago system," in Proceedings of the European Transport Conference, Noordwijkerhout, Netherlands, 2008.

[19] N. G. Harris, "Train boarding and alighting rates at high passenger loads," Journal of Advanced Transportation, vol. 40, no. 3, pp. 249-263, 2006.

[20] N. G. Harris and R. J. Anderson, "An international comparison of urban rail boarding and alighting rates," Proceedings of the Institution of Mechanical Engineers, Part F: Journal of Rail and Rapid Transit, vol. 221, no. 4, pp. 521-526, 2007.

[21] T. Q. Tang, Y. X. Shao, L. Chen, and H. Y. Shang, "Modeling passengers' boarding behavior at the platform of high speed railway station," Journal of Advanced Transportation, vol. 2017, Article ID 4073583, 11 pages, 2017.

[22] D. Li, W. Daamen, and R. M. P. Goverde, "Estimation of train dwell time at short stops based on track occupation event data: A study at a Dutch railway station," Journal of Advanced Transportation, vol. 50, no. 5, pp. 877-896, 2016.

[23] P. B. L. Wiggenraad, Alighting and boarding times of passengers at Dutch railway stations - analysis of data collected at 7 stations in October 2000, TRAIL Research School: Delft University of Technology, Delft, Netherlands, 2001.

[24] W. Heinz, Passenger service times on trains-theory, measurements and models [Ph.D. Thesis], Royal Institute of Technology, Stockholm, Sweden, 2003.

[25] N. G. Harris, $\varnothing$. Risan, and S. Schrader, "The impact of differing door widths on passenger movement rates," WIT Transactions on The Built Environment, vol. 155, pp. 53-63, 2014.

[26] A. Barron, S. Canavan, R. Anderson, and J. Cohen, "Operational impacts of platform doors in metros," Transportation Research Record: Journal of the Transportation Research Board, 2018.

[27] R. Fernández, P. Zegers, G. Weber, and N. Tyler, "Influence of platform height, door width, and fare collection on bus dwell time," Transportation Research Record: Journal of the Transportation Research Board, no. 2143, pp. 59-66, 2010.

[28] S. Seriani and R. Fernandez, "Pedestrian traffic management of boarding and alighting in metro stations," Transportation Research Part C: Emerging Technologies, vol. 53, pp. 76-92, 2015.
[29] G. D. A. Rodríguez, S. Seriani, and C. Holloway, "Impact of platform edge doors on passengers' boarding and alighting time and platform behavior," Transportation Research Record: Journal of the Transportation Research Board, vol. 2540, pp. 102-110, 2016.

[30] S. Seriani, T. Fujiyama, and C. Holloway, "Exploring the pedestrian level of interaction on platform conflict areas at metro stations by real-scale laboratory experiments," Transportation Planning and Technology, vol. 40, no. 1, pp. 100-118, 2017.

[31] S. Seriani and T. Fujiyama, "Experimental study for estimating the passenger space at metro stations with platform edge doors," Transportation Research Record: Journal of the Transportation Research Board, 2018.

[32] C. Holloway, R. Thoreau, T.-R. Roan et al., "Effect of vertical step height on boarding and alighting time of train passengers," Proceedings of the Institution of Mechanical Engineers, Part F: Journal of Rail and Rapid Transit, vol. 230, no. 4, pp. 1234-1241, 2015.

[33] W. Daamen, Y.-C. Lee, and P. Wiggenraad, "Boarding and alighting experiments: Overview of setup and performance and some preliminary results," Transportation Research Record, no. 2042, pp. 71-81, 2008.

[34] R. Fernández, A. Valencia, and S. Seriani, "On passenger saturation flow in public transport doors," Transportation Research Part A: Policy and Practice, vol. 78, pp. 102-112, 2015.

[35] T. Fujiyama, R. Thoreau, and N. Tyler, "The effects of the design factors of the train-platform interface on pedestrian flow rates," Pedestrian and Evacuation Dynamics, pp. 1163-1173, 2012.

[36] X. Karekla and N. Tyler, "Reduced dwell times resulting from train-platform improvements: The costs and benefits of improving passenger accessibility to metro trains," Transportation Planning and Technology, vol. 35, no. 5, pp. 525-543, 2012.

[37] N. Tyler, C. Childs, D. Boampong, and T. Fujiyama, "Investigating ramp gradients for humps on railway platforms," Proceedings of the Institution of Civil Engineers: Municipal Engineer, vol. 168, no. 2, pp. 150-160, 2015.

[38] C. Rudloff, D. Bauer, T. Matyus, and S. Seer, "Mind the gap: Boarding and alighting processes using the social force paradigm calibrated on experimental data," in Proceedings of the 14th IEEE International Intelligent Transportation Systems Conference, ITSC 2011, pp. 353-358, 2011.

[39] T. Kretz, A. Grünebohm, and M. Schreckenberg, "Experimental study of pedestrian flow through a bottleneck," Journal of Statistical Mechanics: Theory and Experiment, no. 10, Article ID P10014, 2006.

[40] S. P. Hoogendoorn and W. Daamen, "Pedestrian behavior at bottlenecks," Transportation Science, vol. 39, no. 2, pp. 147-159, 2005.

[41] A. Seyfried, O. Passon, B. Steffen, M. Boltes, T. Rupprecht, and W. Klingsch, "New insights into pedestrian flow through bottlenecks," Transportation Science, vol. 43, no. 3, pp. 395-406, 2009.

[42] W. Liao, A. Seyfried, J. Zhang, M. Boltes, X. Zheng, and Y. Zhao, "Experimental study on pedestrian flow through wide bottleneck," Transportation Research Procedia, vol. 2, pp. 26-33, 2014.

[43] J. Adrian, M. Boltes, S. Holl, A. Sieben, and A. Seyfried, "Crowding and queuing in entrance scenarios: influence of corridor width in front of bottlenecks," in Proceedings of the 9th International Conference on Pedestrian and Evacuation Dynamics, Lund , Sweden, 2018.

[44] "The Observer. XT software," http://www.noldus.com/observer. 


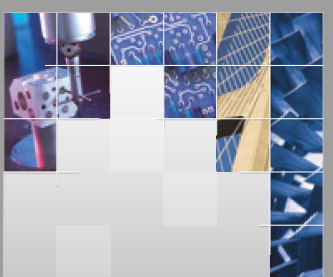

\section{Enfincering}
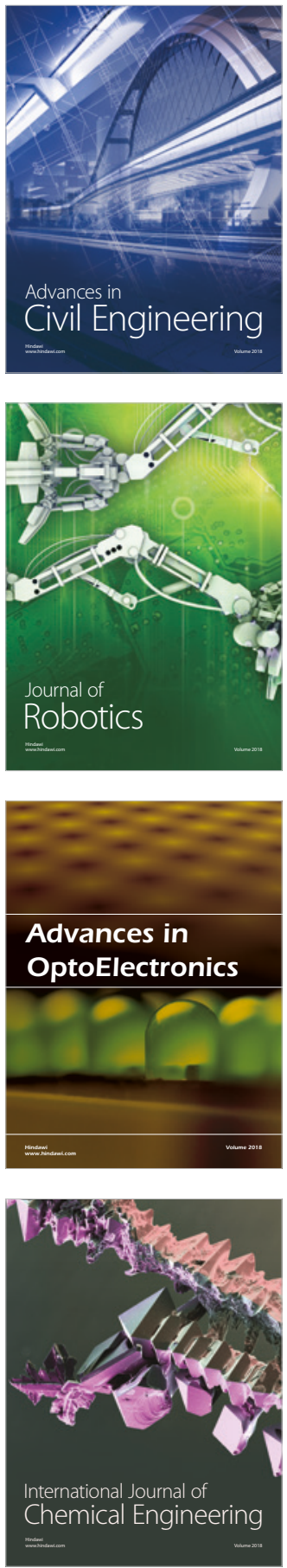

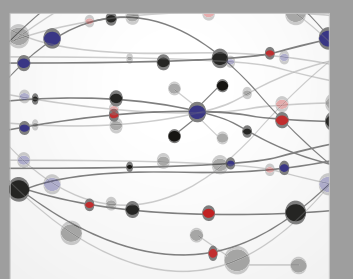

\section{Rotating \\ Machinery}

The Scientific World Journal

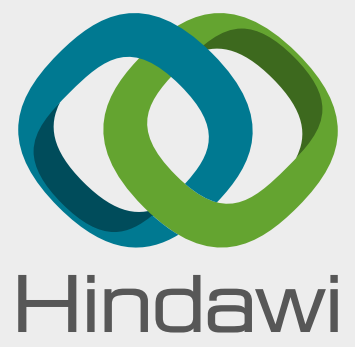

Submit your manuscripts at

www.hindawi.com
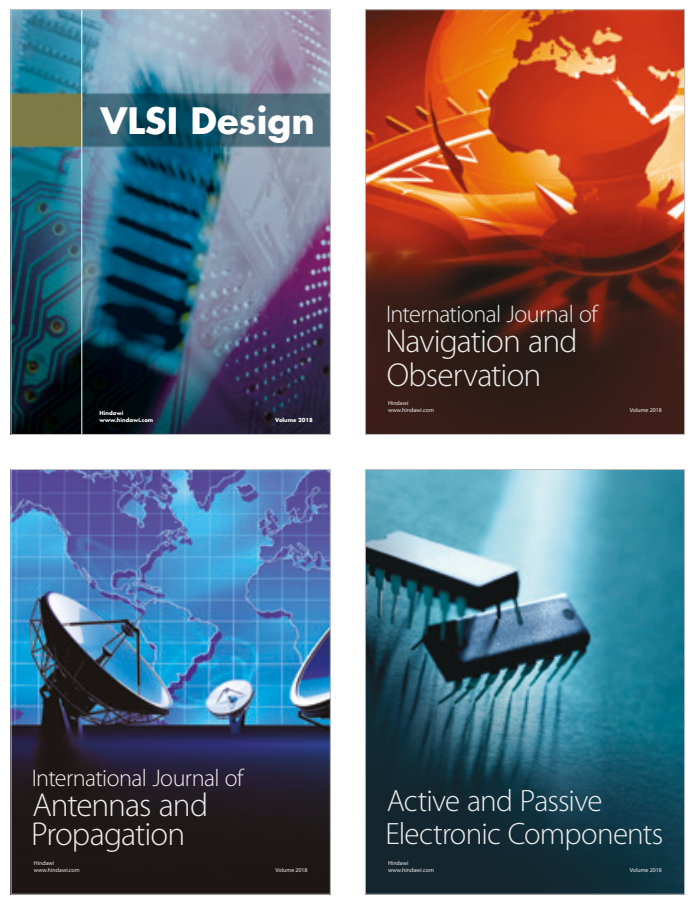
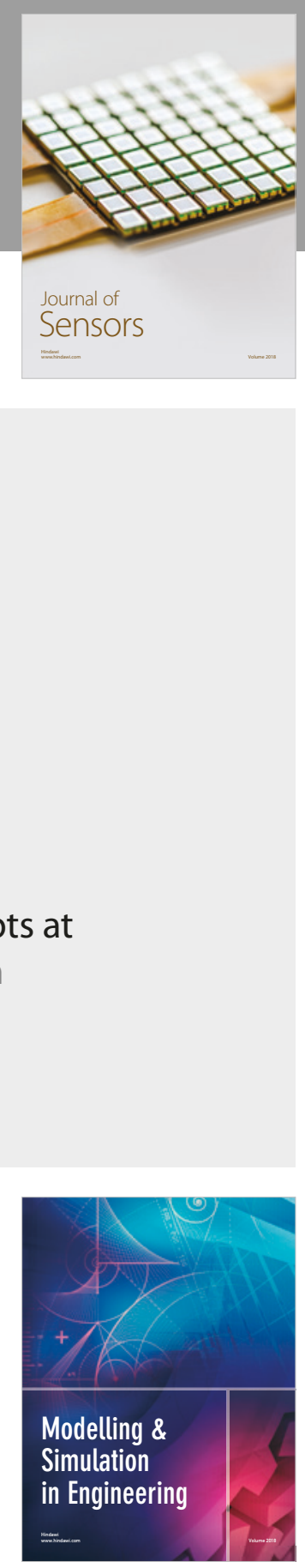

\section{Advances \\ Multimedia}
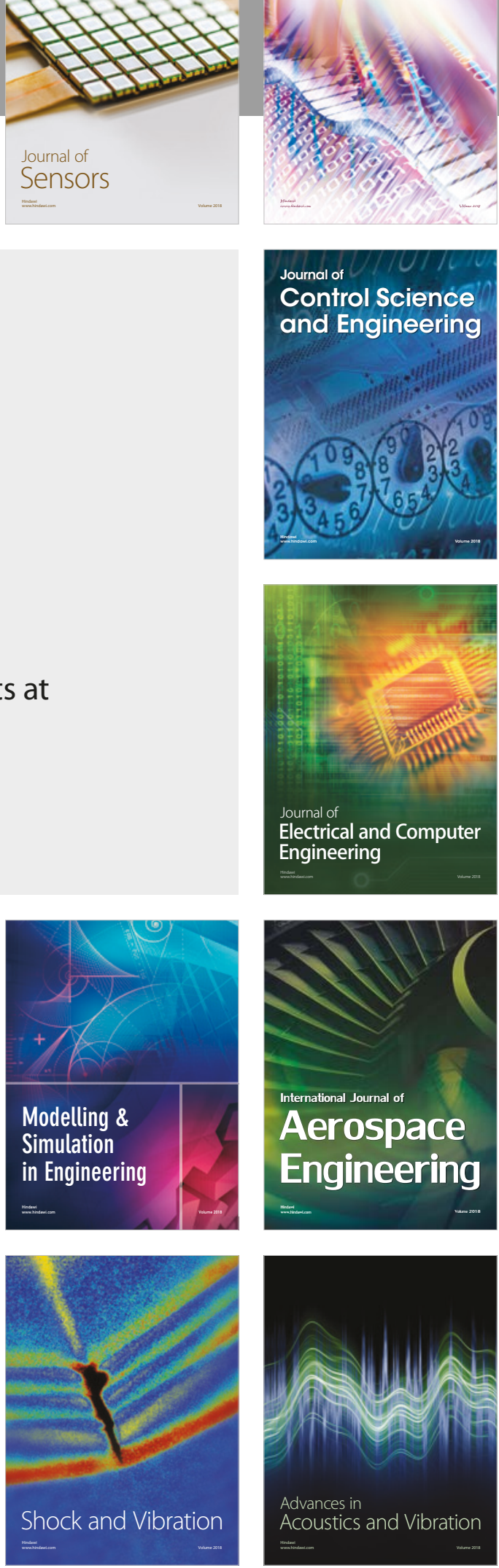